\title{
Belgian Malinois
}

National Cancer Institute

\section{Source}

National Cancer Institute. Belgian Malinois. NCI Thesaurus. Code C53758.

The Belgian Malinois is a muscular dog but not heavy. It has short, erect ears and a short-haired coat that is fawn to red to mahogany with black tips, mask, and ears. There may be some white on the chest and feet. Height: 22-26 inches (56-66 cm.) Weight: 5565 pounds (24-29 kg.) 